and red. These are, however, only seen in the arcs as their lower rim, and by the forward movement one part assumes a red, another a green tint. The red colour sometimes changes into violet or ochre.

The spectroscope I have not had much opportunity of using here, but the well-known auroral "line" I can always see; any others I have not observed.

With regard to the height of the aurora I have, judging from observation, come to the conclusion that it does not appear at a lower elevation here than it does in the south of Norway, while I am convinced that its plane is to be found far above that of the clouds. There has often enough been an opportunity of observing auroræ and clouds simultaneously, but never has there been the slightest indication of the auroræ having descended to the sphere of the clouds, not even under the most violent oscillations and the most intense luminosity and play of colour. In fact I have come to the conclusion that the auroræ which I have watched at Kautokeino are identical with those I have studied in southern latitudes, while their plane is at the elevation which I estimated when choosing Kautokeino as my station of observation.

I may in conclusion state that I have never myself heard the slightest approach to any auroral "noise," and this in spite of my most earnest attention to this somuch-disputed question. Still if I ask the native people (Lapps) about here as to the "noise" there is not a single one who doubts its existence, while several even assert that they have heard it.

I have several times attempted to photograph the aurora borealis, but without success. Thus even by using the most sensitive English "dry" plates, and exposing them from five to seven minutes, I have not obtained a trace of a negative. The cause of this is, I believe, the exceedingly limited substance of light possessed by the auroræ: were thus even the entire heavens flooded by the most intense auroræ, their aggregate lighting capacity would not equal that of the moon when full. I may therefore assume that photographing the aurora borealis is an impossibility.

Kautokeino, Finmarken, Norway, January 28

\section{PROFESSOR HUXLEY ON FDUCATION}

$\mathrm{N}$ the 16 th inst., Prof. Huxley gave an address in connection with the distribution of prizes at the Liverpool Institute, a revised report of which will appear in the next number of the Journal of Education. By the courtesy of the editor of that journal, we are enabled to give a few extracts from Professor Huxley's address. He began by referring to certain propositions which he laid down in the address he gave in Liverpool fourteen years ago as to the practical value of instruction in physical science, its superiority to any other study as a mental discipline, and the certainty that in the future physical science would occupy a much larger share in the time allotted to teaching than had been the case previously. He also laid special stress upon the fact that he was no advocate of the exclusion of other forms of culture from education, but, on the contrary, insisted that it would be a serious mistake to cripple them for the sake of science. He had no sympathy, he said, with a kind of sect or horde of scientific Goths or Vandals who think that it would be proper and desirable to sweep away all other forms of culture and instruction except those in physical science. After referring to the great variety of his past experiences, his familiarity with every form of society, from the uncivilised savage of Papua and Australia, to the occasionally somewhat over-civilised members of our upper ten thousand, and to his interest in every branch of knowledge and form of art, Prof. Huxley insisted on the vast importance of science in education, when properly taught.
He pointed out, however, that unless the knowledge conveyed in the teaching of science or in the teaching of history were actually realised to themselves by the learners, it would be worse than useless.

"Make it as little as you like, but unless that which is taught is based on actual observation and familiarity with facts it is better left alone. There are a great many people who imagine that elementary teaching might be properly carried out by teachers provided with only elementary knowledge. Let me assure you that that is the profoundest mistake in the world. There is nothing so difficult to do as to write a good elementary book, and there is nobody so hard to teach properly and well as people who know nothing about a subject; and I will tell you why. If I address an audience of persons who are occupied in the same line of work as myself I can assume that they know a vast deal, and that they can find out the blunders I make. If they don't, it is their fault and not mine; but when I appear before a body of people who know nothing about the matter, who take for gospel whatever I say, surely it becomes needful that I consider what I say, make sure that it will bear examination, and that I do not impose upon the credulity of those who have faith in me. In the second place, it involves that difficult process of knowing what you know so well that you can talk about it as you can talk about your ordinary business. A man can always talk about his own business. $\mathrm{He}$ can always make it plain; but if his knowledge is hearsay he is afraid to go beyond what he has recollected and put it before those that are ignorant in such a shape that they shall comprehend it. That is why, to be a good elementary teacher, to teach the elements of any subject, requires most careful consideration if you are a master of the subject ; and if you are not a master of it it is needful you should familiarise yourself with so much as you are called upon to teach-soak yourself in it, so to speakuntil you know it as part of your daily life and daily knowledge, and then you will be able to teach anybody. That is what I mean by practical teachers, and although the deficiency is being remedied to a large extent, I think it is one which has long existed, and which has existed from no fault of those who undertook to teach, but because until within the last score years it absolutely was not possible for any one in a great many branches of science, whatever his desire might be, to get instruction which would enable him to be a good teacher of elementary things. All that is being rapidly altered, and I hope it will soon become a thing of the past."

Then as to the important question of time, Prof. Huxley said that all he asked for was that scientific teaching should be put into what politicians and statesmen call the condition of the "most favoured nation"; that is to say, that it shall have as large a share of the time given to education as any other principal subject. On the important question as to what should be regarded as "principal subjects," Prof. Huxley remarked as follows :-

"I take it that the whole object of education is, in the first place, to train the faculties of the young in such a manner as to give their possessors the best chance of being happy and useful in their generation; and, in the second place, to furnish them with the most important portions of that immense capitalised experience of the human race which we call knowledge of various kinds. I am using the term knowledge in its widest possible sense, and the question is what subjects to select, by training and discipline in which the object I have just defined may be best attained. I must call your attention further to this fact, that all the subjects of our thoughts, feelings, and propositions, leaving aside the mere materials and occasions of thinking and feeling-our sensations as all our mental furniture - may be classified under one of two heads : as either within the province of the intellect, something that can be put into proposition and affirmed or denied, 
or as within the province of feeling, or that which, before the name was defiled, was called the æsthetic side of our nature, and which can neither be affirmed nor denied, but only felt and known. According to the classification which I have put before you then, the subjects of all knowledge are divisible into two groups, matters of science and matters of art; for all things with which the reasoning faculty alone is occupied come under the province of science, and, in the broadest sense, and not in the narrow and technical sense in which we are now accustomed to use the word art, all things feelable, all things which stir our emotions, come under the term of art, in the sense of subject matter of the æsthetic province. So that we are shut up to this,-- that the business of education is, in the first place, to provide the young with the means and the habit of observation; and, secondly, to supply the subject matters of knowledge, either in the shape of science or of art, or of both combined. Now, it is a very remarkable fact-but it is true of most things in this world - that there is hardly anything one-sided or of one nature, and it is not immediately obvious what, of the things that interest us, may be regarded as pure science, and what may be regarded as pure art. It may be that there are some peculiarly constituted persons, who, before they have advanced far into the depths of geometry, find artistic beauty about it, but, taking the generality of mankind, I think it may be said that when they begin to learn mathematics their whole souls are absorbed in tracing the connection between the premisses and the conclusions, and that to them, geometry is pure science. So I think it may be said that mechanics and osteology are pure science. On the other hand, melody in music is pure art. You cannot reason about it ; there is no proposition involved in it. So, again, in the pictorial art, an arabesque, or a 'harmony in grey,' touch none but the æsthetic faculty. But a great mathematician, and even many persons who are not great mathematicians, will tell you that they derive intense pleasure from geometrical reasonings. Everybody knows that mathematicians speak of solutions of problems as 'elegant,' and they tell you that a certain mass of mystic symbols is 'beautiful, quite lovely.' Well, you do not see it. They do see it, because the intellectual process, the process of comprehending the reasons symbolised by these figures and these signs, confers upon them a sort of pleasure, such as an artist has in visual symmetry. Take a science of which I may speak with more confidence, and which is the most attractive of those I am concerned with. It is what we call morphology, which consists in tracing out the unity in variety of the infinitely diversified structure of animals and plants. cannot give you any example of a thoroughly æsthetic pleasure more intensely real than a pleasure of this kind - the pleasure which arises in one's mind when a whole mass of different structures runs into one harmony as the expression of a central law. That is where the province of art overlaps and embraces the province of intellect. And if I may venture to express an opinion on such a subject, the great majority of forms of art are not in the sense what $I$ just now defined them to be-pure art; but they derive much of their quality from simultaneous and even unconscious excitement of the intellect. When I was a boy I was very fond of music, and I am so now; and it so happened that I had the opportunity of hearing much good music. Among other things, I had abundant opportunities of hearing that great old master, Sebastian Bach. I remember perfectly well---though I knew nothing about music then, and I may add know nothing whatever about it now-the intense satisfaction and delight which I had in listening by the hour together to Bach's fugues. It is a pleasure which remains with me, I am glad to think; but of late years I have tried to find out the why and wherefore, and it has often occurred to me that the pleasure, in musical compositions of this kind, is essentially of the same nature as that which is derived from pursuits which are commonly regarded as purely intellectual. I mean that the source of pleasure is exactly the same as in most of my problems in morphology - that you have the theme in one of the old masters' works followed out in all its endless variations, always appearing and always reminding you of unity in variety. So in painting; what is called truth to nature is the intellectual element coming in, and truth to nature depends entirely upon the intellectual culture of the person to whom art is addressed. If you are in Australia, you may get credit for being a good artist-I mean among the natives-if you can draw a kangaroo after a fashion. But among men of higher civilisation the intellectual knowledge we possess brings its criticism into our appreciation of works of art, and we are obliged to satisfy it as well as the mere sense of beauty in colour and in outline. And so the higher the culture and information of those whom art addresses, the more exact and precise must be what we call its 'Truth to nature.' If we turn to literature, the same thing is true, and you find works of literature which may be said to be pure art. A little song of Shakespeare or of Goethe is pure art, although its intellectual content may be nothing. A series of pictures is made to pass before your mind by the meaning of words, and the effect is a melody of ideas. Nevertheless the great mass of the literature we esteem is valued not merely because of having artistic form, but because of its intellectual content, and the value is the higher the more precise, distinct, and true is that intellectual content. And if you will let me for a moment speak of the very highest forms of literature, do we not regard them as highest simply because the more we know the truer they seem ; and the more competent we are to appreciate beauty, the more beautiful they are? No man ever understands Shakespeare until he is old, though the youngest may admire him; the reason being that he satisfies the artistic instinct of the youngest and harmonises with the ripest and richest experience of the oldest. I have said this much to draw your attention to what, to my mind, lies at the root of all this matter, and at the understanding of one another by the men of science on the one hand, and the men of literature and history and art on the other. It is not a question whether one order of study should predominate or that another should. It is a question of what topics of education you shall select which will combine all the needful elements in such due proportion as to give the greatest amount of food and support and encouragement to those faculties which enable us to appreciate truth, and to profit by those sources of innocent happiness which are open to us, and at the same time to avoid that which is bad and coarse and ugly, and to keep clear of the multitude of pitfalls and dangers which beset those who break through the natural or moral laws."

Professor Huxley then went on to point out the worthlessness of the kind of literary education that used to prevail in English schools, and gave his idea of what a literary education ought to be. If, he said, he could make a clean sweep of everything, and start afresh, he would in the first place secure the training of the young in reading and writing, and in the habit of attention and observation both to that which is told them and that which they see; and he would make it absolutely necessary for everybody, for a longer or shorter period, to learn to draw, and there is nobody who cannot be made to draw more or less well.

"Then we come to the subject-matter, whether scientific or æsthetic, of education, and I should naturally have no question at all about teaching the elements of physical science of the kind I have sketched in a practical manner; but among scientific topics, using the word 'scientific' in the broadest sense, I would also include the elements of the theory of morals and 
of that of political and social life, which, strangely enough, it never seems to occur to anybody to teach a child. I would have the history of our own country and of all the influences which have been brought to bear upon it, with incidental geography, not as a mere chronicle of reigns and battles, but as a chapter in the development of the race and the history of civilisation. Then with respect to æsthetic knowledge and discipline, we have happily in the English language one of the most magnificent storehouses of artistic beauty and of models in literary excellence which exists in the world at the present time. I have said before, and I repeat it here, that if a man cannot get literary culture of the highest kind out of his Bible, and Chaucer, and Shakespeare, and Milton, and Hobbes, and Bishop Berkeley, to mention only a few of our illustrious writers-I say if he cannot get it out of those writers, he cannot get it out of anything; and I would assuredly devote a very large portion of the time of every English child to the careful study of the models of English writing of such varied and wonderful kind as we possess, and what is still more important and still more neglected, the habit of using that language with precision and with force and with art. I fancy we are almost the only nation in the world who seem to think that composition comes by nature. The French attend to their own language, the Germans study theirs; but Englishmen do not seem to think it is worth their while. Nor would I fail to include in the course of study I am sketching translations of all the best works of antiquity or of the modern world. It is a very desirable thing to read Homer in Greek; but if you don't happen to know Greek, the next best thing is to read as good a translation of it as we have recently been furnished with in prose. You won't get all you would get from the original, but you may get a great deal, and to refuse to know this great deal because you cannot get all seems to be as sensible as for a hungry man to refuse bread because he cannot get partridge. Finally, I would add instruction in either music or painting, or if the child should be so unhappy, as sometimes happens, to have no faculty for 'either of these, and no possibility of doing anything in an artistic sense with them, then I would see what could be done with literature alone; but I would provide in the fullest sense for the development of the æsthetic side of the mind. In my judgment these are all the essentials of education for an English child." Prof. Huxley concluded by saying that if the educational time permitted, there were one or two things he should be inclined to add to these essentials (which fitted an Englishman to go anywhere or to enter on any career); among these additional subjects he mention ed Latin and German. Beyond that, let each man take up his special line.

\section{NOTES}

The Emperor of Germany has raised Prof. Helmholtz to noble rank.

THE two English observers, Messrs. Lawrence and Woods, detailed to secure photographs of the total eclipse of the sun on May 6, left Southampton for Panama on Saturday last. The operations will be exclusively photographic. The Treasury only determined to grant the necessary funds some fifteen days before the last date on which the observers could sail; the instruments sent out, therefore, were most hurriedly put together; and the greatest praise is due to Messrs. Hilger and Meagher for their work against time. Detailed instructions and a time table stating the work to be done for every second from ten minutes before totality till ten minutes afterwards, have been sent with the observers. If all goes well more than fifty photographs will be secured.

IN reply to the Memorial addressed to the Council of the British Association on the subject of the proposed meeting of the Association in Canada in 1884, signed by 144 members of the General Conmittee, Mr. Bonney states that the Council of the British Association are fully alive to the difficulties which will attend the visit to Canada decided upon by the General Committee at Southampton in August last. As this decision was obtained in accordance with the usual forms and does not appear to contravene the expresi wording of the rules of the Association, the Council feel bound to recognise it as a valid one, and believe that they would not be justified in summoning a special meeting of the General Committee to reconsider the question. They have, however, in effect already taken steps to ascertain the general feeling of the members of the Association. In the month of November last, after a consultation with Sir A. T. Galt, the Hish Commis:ioner for Canada in this country, the officers of the Association addressed to their intending hosts in Montreal a number of questions, upon the answers to which the success of the projected visit must greatly depend. To the e questions they are now daily expecting a reply. As soon as this is received, information will be given to the Members of the Association, and inquiries made as to their willingness to visit Canada. The replies will enable the Council to judge whether it will be possible to hold a successful and fairly representative meeting at Montreal.

M. Raoul Pictet has recently tried, on the Lake of Geneva, a specimen of his " rapid vessel," the general idea of which was indicated a short time ago. The vessel is figured in Archives des Sciences for January, and M. Pictet gives details of the theory and working. With a length of about 67 feet, and a width of I 3 feet, this vessel is peculiar chiefly in having a bottom that is of parabolic form lengthwise, the concavity downwards; trans. versely the bottom is nearly straight; the sides are vertical. A keel reaching from about the middle of the length, incloses a screw shaft. Among other results M. Pictet shows that the force of traction of this vessel is always less than that of an ordinary vessel of the same general form and going at the same rate. The advantages of the parabolic curve only become apparent at a certain speed, depending on the width, leng b, and tonnage, and the parameters of the parabolic curve. The force of traction passes through a maximum, at a certain velocity for each vessel ; beyond that point, the work of the motor, and so the expenditure of fuel, diminishes, though the speed increases. Experiment bas yet to decide the limits of this second period. The emergence of the vessel, very small for small velccity, grows very quickly when a speed of 5 metres (say I 7 feet) per second has been reached; and it converges rapidly towards an upper limit. The recoil of the screw for different velocities increases to a maximum, then constantly diminishes and tends to become nil for an infinite velocity. For other features of the action we must refer to the original. The engine we note proved faulty, and in several of the experiments the vessel was towed by a steamer, at velocities rising to 27 kilometres (say 17 miles); when tbis last is reached, an economy of one-half is realised (growing from 16 kilometres).

THE recent death of the Rev. Titus Coan, an aged and much-esteemed missionary at Hilo, Hawaii (where he laboured nearly forty-eight years), has been announced ( $A m$. Fourn. Sci.). He tcok a deep interest in the volcanic mountain at whose foot he lived, and at each eruption was generally the first on the ground to observe and report on the movements. Three times he ascended to the scenes of the eruptions connected with the summit crater. Though not a geologist, his accounts (many of them in the journal named) have always been of geological value. $\mathrm{He}$ was the principal historian of the great eruption of Kilauea in 1840 , and the summit eruption of 1843 , when the flow was uninterrupted for twenty-five miles and continued six weeks. It was after the latter eruption that he made the very imfurtant observation (since confirmed) that 